Short Communication

\title{
Investigation of Corrosion Inhibition Effect of Enprofylline Drug on Mild Steel Corrosion in Sulphuric Acid Solution
}

\author{
Yin Liangtian ${ }^{1}$, Man Zhang ${ }^{2}$, Chen Shidong ${ }^{3}$, Tian Yunji ${ }^{4}$, Wu Haixia ${ }^{5, *}$ \\ ${ }^{1}$ Research Institute of Oil Production Technology, The Seventh Oil Extraction Plant of Petrochina \\ Changqing Oil Field Company, Xian, Shanxi province, China-710000. \\ ${ }^{2}$ Research Institute of Oil Production Technology, The Fifth Oil Extraction Plant of Petrochina \\ Changqing Oil Field Company, Xian, Shanxi province, China-710000. \\ ${ }^{3}$ Research Institute of Oil Production Technology, The Sixth Oil Extraction Plant of Petrochina \\ Changqing Oil Field Company, Xian, Shanxi province, China-710000. \\ ${ }^{4}$ Research Institute of Oil Production Technology, The Tenth Oil Extraction Plant of Petrochina \\ Changqing Oil Field Company, Xian, Shanxi province, China-710000. \\ ${ }^{5}$ School of Chemical and Pharmaceutical Engineering, Hebei University of Science and Technology, \\ Shijiazhuang, Hebei, China-050018. \\ *E-mail: wuhaixiawjj@163.com
}

doi: $10.20964 / 2020.06 .83$

Received: 9 February 2020 / Accepted: 1 April 2020 / Published: 10 May 2020

The drug Enprofylline (DE) [3-propylxanthine)] was examined as potential corrosion inhibitor of mild steel in $1 \mathrm{M}$ sulphuric acid $\left(\mathrm{H}_{2} \mathrm{SO}_{4}\right)$ media using weight loss, electrochemical, surface and quantum chemical studies. DE is basically a bronchodilator and has been used in treatment of asthma for a very long time. This drug was chosen due to its non-toxicity, ease of availability and low cost. The presence of nitrogen and oxygen $(\mathrm{N}, \mathrm{O})$ heteroatoms in the molecular structure makes it potential inhibitor for corrosion of mild steel in sulphuric acid. The electrochemical tests including open circuit potential (OCP), electrochemical impedance spectroscopy (EIS), and potentiodynamic polarization (PDP) showed good mitigation efficiency of $\mathrm{DE}$ in $1 \mathrm{M} \mathrm{H}_{2} \mathrm{SO}_{4}$ media. The variation of the anodic and cathodic slopes reflected that the DE belongs to mixed category. All the electrochemical results were close to each other vindicating the spontaneity of the tests. The surface studies were done using scanning electrochemical microscopy (SECM) and scanning electron microscopy with energy dispersive spectroscopy (SEMEDS). Theoretical simulations were done using Gaussian 9.0 software for windows using density functional theory (DFT). The DFT simulations were done for both neutral and protonated molecules to get better idea of the mechanism of action.

Keywords: Enprofylline, Mild steel, $\mathrm{H}_{2} \mathrm{SO}_{4}$, Corrosion inhibition, EIS, SECM 
(C) 2020 The Authors. Published by ESG (www.electrochemsci.org). This article is an open access article distributed under the terms and conditions of the Creative Commons Attribution license (http://creativecommons.org/licenses/by/4.0/). 